Original Research Article

\title{
Dermatological adverse drug reactions in tertiary care hospital: an analysis of causality and severity
}

\author{
Kalpana R. Bharani, Nitibhushansingh R. Chandel*, Chhaya A. Goyal
}

Department of Pharmacology, SAIMS Medical College \& PG Institute, Indore, Madhya Pradesh, India

Received: 31 May 2018 Accepted: 26 June 2018

*Correspondence to: Dr. Nitibhushansingh R. Chandel,

Email: dr.nitinsingh1@ gmail.com

Copyright: (C) the author(s), publisher and licensee Medip Academy. This is an openaccess article distributed under the terms of the Creative Commons Attribution NonCommercial License, which permits unrestricted noncommercial use, distribution, and reproduction in any medium, provided the original work is properly cited.

\begin{abstract}
Background: Dermatological adverse drug reactions (ADRs) are easily detected by patients and that precludes further usage of drugs. So, decided to study the pattern, causative drugs, severity of adverse drug reactions and their causality in tertiary care hospital.

Methods: It was prospective non inventional cross sectional study. Patients attending OPD or admitted to IPD of all age group and both gender with suspected dermatological ADRs following drug intake were included and the ADRS were recorded on CDSCO's Pharmacovigilance form. Collected data was analyzed for assessment of causality using WHO-UMC scale, for severity by using Modified Hartwig and Siegel. Morphological pattern, drug groups, gender and age distribution was analyzed.

Results: 231 dermatological ADRs were recorded and analyzed. Maximum cases were found in 21-30 years age group (74 cases). Dermatological ADRs were found in 143 females and in 88 males. Three major classes of drugs found responsible for causing dermatological ADRs were -oral Antimicrobials-41 $(17.75 \%)$ and Injectable Antimicrobials-40 (17.32\%), NSAID's-40 (17.32\%.) and Topical Betnovate-36 (15.58\%.). Regarding the type, 95 cases were of maculopapular rashes (41.12\%), steroid damaged face in $42(18.18 \%)$ andacute urticaria in $20(8.65 \%)$. In terms of Severity assessment, authors found 23 cases $(9.95 \%)$ as Mild, 176 cases $(76.19 \%)$ of moderate severity and 32 cases $(13.85 \%)$ of Severe category. In terms of causality assessment: 3 cases as Certain, 68 cases as Probable and 160 cases as Possible.

Conclusions: From this study, it was found maximum Dermatological ADRs of moderate severity and few cases of causality category as "Certain".
\end{abstract}

Keywords: Causality, Dermatological adverse drug reaction, Severity

\section{INTRODUCTION}

Adverse drug reactions (ADR's) are of great concern to the general public, the pharmaceutical industry, the regulatory authorities and the medical profession. The growing number of newly approved drugs coupled with the complex treatment modalities, have contributed to an increased risk of ADR's. ${ }^{1}$ They are common occurrences in hospital setting and more so in community and is attributed to the severity and complexity of the disease process, use of multiple drugs, drug interactions and possible negligence on the part of the patient and the physician. ${ }^{2}$ An Adverse event/adverse experience is defined as any untoward medical occurrence that may present during treatment with a pharmaceutical product but which does not necessarily have a causal relationship with this treatment. ${ }^{3}$ It may or may not be due to drug. ${ }^{4}$ These are important for clinical phenomenon occurring during drug treatment where causality cannot be or is not to be ascertained $^{(5)}$ Thus an ADR can be defined as an adverse event with a causal link to a drug. ${ }^{5}$

\section{Terms related to adverse drug reaction}

Unexpected Adverse reaction is an adverse reaction, the nature or severity of which is not consistent with domestic 
labeling or marketing authorization or expected from characteristics of the drug. ${ }^{3}$

A serious Adverse Event or Reaction is defined as any untoward medical occurrence that at any dose results in death or acquires inpatient hospitalization or prolongation of existing hospitalization or results in persistent or significant disability or incapacity. ${ }^{3}$

Fatal ADE is an adverse event in which, a drug, in all likelihood, substantially contributed to patient death. ${ }^{3}$

Side effects are unwanted, unavoidable and undesirable effect of a pharmaceutical product occurring at doses normally used in man, which is related to the pharmacological properties of the drug although the usual impression is that these are harmful effects, it may not necessarily be so and generally they disappear on drug withdrawal. ${ }^{3}$ A side effect in one clinical condition may be utilized as a therapeutic effect in another (digoxin, antihistaminics, and atropine). ${ }^{6}$

\section{Types according to their severity}

The term severity is used to describe the intensity of a specific event as mild, moderate and severe. However, the event may be of relatively minor medical significance (such as severe headache). ADR severity assessment can be done using modified Hartwig and Siegel. ${ }^{7}$

\section{Diagnosis of ADR}

ADR may be difficult to diagnose because they are rarely specific or clearly recognizable, can resemble many disease or can affect any tissue or organ. Therefore, it is important that whenever a patient presents with a complaint, the possibility of ADR as the cause should be considered in the differential diagnosis. ${ }^{8}$

\section{Causality assessment}

Causality assessment of ADRs is the structured and standardized assessment of individual patient/ case report of the likelihood of involvement of suspected drug in causing particular event in a given patient. The various information analyzed for causality assessment include the complete knowledge about clinical event, baseline symptoms of the patient, medication details, complete medical history of patient, possible drug interactions and outcomes of the reaction upon de challenge and/or re challenge. There are many systems used to assess the subject causality relationships such as: ${ }^{9}$

- WHO assessment scale.

- Naranjo scale.

- European scale.

- Arch and lasagna' scale.

- Kramer scale.

- Bayesian neural network.
- Yale scale.

- Spanish quantitative computation system.

\section{WHO assessment scales}

Various criteria required for assessment of causality includes knowledge about nature of the reaction, any temporal time relationship with the event, previous reports on reported reaction, dechallenge, rechallenge and other possible alternate causes. The causal relationships have been categorized as certain, probable, unlikely, conditional and unassessable. ${ }^{10}$

\section{Epidemiology of dermatological Adverse Drug Reactions}

In a study examining the incidence of dermatological adverse in spontaneous ADRs reported in Italy, over $30 \%$ of all reported ADRs were dermatological in nature. ${ }^{11}$ This is higher than other studies, where dermatological adverse drug reactions comprise $10 \%$ to $20 \%$ of reported ADRs and it still holds a substantial fraction among all reactions. ${ }^{11}$

Among all hospitalized patients, the incidence of dermatological adverse drug reaction has been found to range from $1 \%$ to $3 \%$, but studies performed on and after 1989 varies from $2 \%$ to $5 \%$ of hospitalized patients and approximately 1 in 1000 hospital patients suffer from lifethreatening dermatological drug reactions. ${ }^{12,13}$

\section{Cost to the health care system}

Based on the frequency of drug ingestion and the incidence of dermatological adverse drug reaction for in- patients, from the Boston Collaborative Drug Surveillance program in 1991, it was estimated that around 2.25 million patients in the United States experience dermatological adverse drug reactions each year. ${ }^{14}$

Dermatological adverse drug reactions clearly represent a significant burden on the health care system, in addition to be a frequent reason for cessation of otherwise effective drug therapy in patients.

With this background we decided to undertake a study for assessing the pattern, severity and causality of Adverse drug reactions in this tertiary care hospital setting.

\section{METHODS}

The study of dermatological manifestations of adverse drug events was started after taking permission from the Institutional ethics committee.

Written informed consent was not taken as all the patients attending the Skin OPD elaborated their complaints regarding the dermatological manifestations of adverse drug events to a qualified dermatologist and we shared the same information. Verbal consent was taken from all the 
patients. Additional information regarding the drug history, time of onset of reaction, any previous history of same and concomitant drugs intake was taken by us, which the patients provided willingly. The above information was obtained using CDSCO's suspected adverse drug reaction reporting form.

It was a cross sectional observational study. Location of study was SAIMS Medical College and PGI, Indore (M.P.). Patients attending OPD or admitted to IPD with suspected dermatological adverse drug reactions following drug intake. Time duration was about one year.

\section{Inclusion criteria}

Patients of all ages and both sexes taking drugs of any category who developed suspected adverse drug event.

\section{Exclusion criteria}

Repeat dermatological adverse drug reactions with the same drug and patients having skin disease per se.

\section{Data collection and analysis}

Data of adverse drug reactions was collected on CDSCO's suspected adverse drug reaction reporting form. Collected data was analyzed for assessment of causality using WHOUMC scale, for severity by using Modified Hartwig and Siegel ${ }^{7)}$, for pattern of ADE, for drug groups causing Dermatological ADRs, for gender and age distribution. Percentages and proportions were used to find out the order of offending drugs, pattern and gender age distribution.

\section{RESULTS}

\section{Causative drugs for dermatological adverse drug reactions}

In this study 231 cases were observed for dermatological drug reactions in study period. Amongst them, the 3 major classes of drugs frequently responsible for causing dermatological drug reactions were- oral Antimicrobials41 (17.75\%), Injectable Antimicrobials-40 (17.32\%), NSAID's-40 (17.32\%) and Topical Betnovate-36 (15.58\%) (Table 1).

\section{Types of dermatological adverse drug reactions}

Regarding the type of dermatological drug reactions, out of 231 cases, 95 cases were of maculopapular rashes $(41.12 \%)$, next being steroid damaged face in $42(18.18 \%)$ followed by acute urticaria in $20(8.65 \%)$ patients (Table 2).

\section{Miscellaneous includes}

Folliculitis-1, Drug induced blisters-1, Eruptions with crusting-1, Contact dermatitis-1, Tinea incognito-1,
Application site reaction-1, Acneiform dermatitis-1, Drug induced acne-1, Lichenoid drug eruption-1 Palmo-Planter pustulosis-1, Seborrhic dermatitis-1 and Exfoliative dermatitis with severe itching-1.

Table 1: Causative drugs for dermatological adverse drug reactions.

\begin{tabular}{|lll|}
\hline Causative Drug & $\begin{array}{l}\text { Number } \\
\text { of cases }\end{array}$ & Percentage \\
\hline Oral Antimicrobials & 41 & 17.75 \\
\hline Injectable Antimicrobials & 40 & 17.32 \\
\hline NSAID' S & 40 & 17.32 \\
\hline Topical Betnovate & 36 & 15.58 \\
\hline Anti-epileptics & 18 & 7.79 \\
\hline Anti-cancer & 13 & 5.63 \\
\hline Blood and it's products & 12 & 5.19 \\
\hline $\begin{array}{l}\text { Topical clobetasole with } \\
\text { gentamicin }\end{array}$ & 10 & 4.33 \\
\hline Oral steroids & 8 & 3.46 \\
\hline Anti- Tubercular & 8 & 3.46 \\
\hline Iron with Multivitamins & 5 & 2.16 \\
\hline
\end{tabular}

Table 2: Percentage of different dermatological adverse drug reactions adverse drug reactions.

\begin{tabular}{|lll|}
\hline $\begin{array}{l}\text { Type of dermatological } \\
\text { reaction }\end{array}$ & $\begin{array}{l}\text { Number } \\
\text { of cases }\end{array}$ & Percentage \\
\hline Maculopapular rashes & 95 & 41.12 \\
\hline Steroid damaged face & 42 & 18.18 \\
\hline Acute urticaria & 20 & 8.65 \\
\hline Fixed drug eruption & 18 & 7.79 \\
\hline Aloplecia & 11 & 4.76 \\
\hline $\begin{array}{l}\text { Injection site redness and } \\
\text { itching }\end{array}$ & 8 & 3.46 \\
\hline Erythema Multiforme & 7 & 3.03 \\
\hline Steven Jhonson syndrome & 4 & 1.73 \\
\hline Facial swelling with itching & 3 & 1.29 \\
\hline Acneform eruptions & 3 & 1.29 \\
\hline Toxic epidermal necrolysis & 2 & 0.86 \\
\hline Angioedema & 2 & 0.86 \\
\hline Steroid induced purpura & 2 & 0.86 \\
\hline $\begin{array}{l}\text { steroid induced cushing } \\
\text { syndrome }\end{array}$ & 2 & 0.86 \\
\hline Miscellaneous & 12 & 5.19 \\
\hline
\end{tabular}

In Severity assessment of various dermatological adverse drug reactions caused by different categories of drugs authors found 23 cases $(9.95 \%)$ as Mild, 176 cases $(76.19 \%)$ as of moderate severity and 32 cases $(13.85 \%)$ as Severe category (Table 3).

Causality assessment of dermatological adverse drug reactions as per WHO UMC scale. Authors found only 3 cases as Certain, 68 cases as Probable and 160 cases as Possible. Regarding age group-maximum cases were found in 21-30 years age group (74 cases), followed by 3140 years age group (37 cases) and 11-20 years age group 
(36 cases). Minimum cases were found in 0-10 years age group ( 8 cases).

Table 3: Severity assessment of various dermatological adverse drug reactions caused by different categories of drugs.

\begin{tabular}{|llll|}
\hline Drug & Mild & Moderate & Severe \\
\hline $\begin{array}{l}\text { Anti Microbial } \\
(81)\end{array}$ & $\begin{array}{l}6 \\
(7.40 \%)\end{array}$ & $\begin{array}{l}65 \\
(80.24 \%)\end{array}$ & $\begin{array}{l}10 \\
(12.34 \%)\end{array}$ \\
\hline NSAIDS (40) & $04(10 \%)$ & $28(70 \%)$ & $08(20 \%)$ \\
\hline $\begin{array}{l}\text { Topical } \\
\text { Betnovate (36) }\end{array}$ & Nil & $36(100 \%)$ & Nil \\
\hline $\begin{array}{l}\text { Anti Epileptics } \\
(18)\end{array}$ & 01 & 10 & 07 \\
\hline Steriods (08) & NIL & $06(75 \%)$ & $02(25 \%)$ \\
\hline $\begin{array}{l}\text { Anti Tubercular } \\
\text { drugs (08) }\end{array}$ & NIL & $05(62.5 \%)$ & $\begin{array}{l}03 \\
(37.5 \%)\end{array}$ \\
\hline $\begin{array}{l}\text { Blood and its } \\
\text { products(12) }\end{array}$ & $\begin{array}{l}01 \\
(8.33 \%)\end{array}$ & $\begin{array}{l}10 \\
(83.33 \%)\end{array}$ & $\begin{array}{l}01 \\
(8.33 \%)\end{array}$ \\
\hline $\begin{array}{l}\text { Topical } \\
\text { clobetasole+ } \\
\text { Gentamicin }(10)\end{array}$ & $02(20 \%)$ & $08(80 \%)$ & Nil \\
\hline $\begin{array}{l}\text { Anti Cancer } \\
\text { drugs (13) }\end{array}$ & $\begin{array}{l}08 \\
(61.53 \%)\end{array}$ & $\begin{array}{l}05 \\
(38.46 \%)\end{array}$ & Nil \\
\hline $\begin{array}{l}\text { Iron and Multi } \\
\text { Vitamins (05) }\end{array}$ & $01(20 \%)$ & $03(60 \%)$ & $01(20 \%)$ \\
\hline $\begin{array}{l}23 \\
\text { Total }\end{array}$ & $\begin{array}{l}176 \\
(76.19 \%)\end{array}$ & $\begin{array}{l}32 \\
(13.85 \%)\end{array}$ \\
\hline
\end{tabular}

Gender wise distribution of dermatological ADRs. Out of 231 total cases, 143 cases of dermatological adverse drug reactions were found in females and 88 in males

\section{DISCUSSION}

Dermatological (dermatological) drugs reactions are the most frequently occurring adverse reactions to drugs. Although the rate of acute severe adverse dermatological reactions to medication is low, these reactions can affect anyone who takes medication and can result in disability or death. ${ }^{4}$ Even a small number of cases associated with a particular drug may alter the recommendations for its use. ${ }^{5}$ Therefore the impact is significant in terms of cost and health service resources. ${ }^{6}$

Very few studies related with dermatological manifestations of Adverse Drug Reactions have been carried out in India until date, hence, we decided to carry out this study in population from central India. ${ }^{15-22}$

Different studies have reported different incidence rates, which vary from $2 \%$ to $30 \% .^{11-13}$ In this study, authors did not try to find out incidence, as the data regarding total number of ADRs at our Hospital was not available.

Authors have analyzed the data in comparison to research available from India because in other countries apart from spontaneous (voluntary) reporting systems other reporting systems also exist. Therefore, the frequency and proportions of dermatological ADRs from Indian System of Reporting cannot be matched (compared) with data from other reporting systems. Only cases of serious dermatological ADRs (for ex, TEN, SJS, EFD) can be matched as they ought to be reported in any Pharmacovigilance system.

In this study $61.90 \%$ of Females reported dermatological ADRs as compared to $38.10 \%$ Males, which is approximately equal to $61.16 \%$ Females, as reported by Chatterjee, et al, Inbaraj S.D et al, $(52.5 \%$, Females) and Abanti S, et al, (51\%, females) It is different from Hiware $\mathrm{S}$, et al, who has reported a male preponderance of $64.22 \%{ }^{18-21}$ As regards to age group, maximum number of cases was from age group 21-30 years $(32.03 \%)$ and age group of $31-40$ years $(16.01 \%), 11-20$ years $(15-58 \%), 51-$ 60 years $(13.42 \%)$. This distribution of dermatological ADRs across different age groups matches to that reported by Hiware $S$, et al, Abanti S, et al, Chatterjee $S$, et al. ${ }^{18,19,21}$

In this study, authors found out that, Oral and Injectable Antimicrobials (35\%) are the leading cause of the dermatological ADRs. This finding is less than that of $55.5 \%, 50.9 \%$ and $39.1 \%$ as reported by other groups. ${ }^{18-20}$ It is approximately near $(34.10 \%)$ to study done by Chatterjee. S, et al, and Ghosh. S, et al, (30\%). ${ }^{21,22}$

The second leading cause of dermatological ADRs in this study is NSAIDs (17.32\%) which is approximately near to $18.56 \%$ reported by another group but differs with research from eastern India $(11.3 \%) .{ }^{18,19} \mathrm{It}$ is much lesser than reported by other researchers $(39.1 \%) .{ }^{20}$ It is the third leading cause $(21.50 \%)$ as reported by Chatterjee $\mathrm{S}$, et al. ${ }^{21}$

Topical steroids (betnovate) is related with $15.58 \%$ cases of dermatological ADRS, whereas others (12.61\%). ${ }^{18}$ Have also reported it to be third leading cause. This differs with other group who has reported Antiepileptic (11.3\%) to be the Third leading cause of ADRs. ${ }^{19}$

This also differs from Inbaraj S.D et al, who have reported oral steroids $(8.5 \%)$ and Topical Steroids $(6.8 \%)$ as third and fourth leading cause respectively of dermatological ADRS. ${ }^{20}$

Abanti, et al, has reported Allopurinol as fourth cause of dermatological ADRs where as in this study Anti epileptics (7.79\%) occupy the fourth position as offending drugs for dermatological ADRs. In this study, dermatological ADR with Allopurinol was not detected. ${ }^{19}$

Chatterjee S, et al, and Ghosh S, et al found Antiepileptic to be the second leading cause of dermatological ADRs (32.88\% and $25 \%$ respectively) with a sample size of 739 and 53 patients respectively. ${ }^{21,22}$

The reason for this can be that in the study done by Abanti, et al, Arthritis was the fourth leading Indication for the Prescriptions. 
In this study, anticancer drugs $(5.63 \%)$ were the fifth leading offender drugs. Hirwe, et al, and Abanti, et al, did not mention Anti-Cancer drugs as the cause of dermatological ADRs. ${ }^{18,19}$ This can be because of the fact that in this Institution there is Medical and Surgical Oncology department catering to cancer patients.

In the present research work, authors found out that $5.19 \%$ ADRs have been caused by Blood and Blood Products. The other groups have not mentioned Blood and Blood products as cause for single dermatological ADRs. ${ }^{18-21}$

Maculopapular rash (41.12\%) was the most commonly occurring dermatological ADR in this study. Similar results $(37.73 \%)$ have been reported by Hiware. S, et al, Ghosh S, et.al, whereas Chatterjee S, et.al, has reported Maculopapular rash $(25.43 \%)$ as second commonest reaction, which was marginally lower then Urticaria $(27.19 \%)$ as First commonest reaction, in their study. ${ }^{18,21,22}$ Inbaraj SD, et al, has also reported urticaria (32.2\%) as the most commonest form of Dermatological ADR. ${ }^{20}$

Steroid damaged face has been the second commonest $(18.18 \%)$ ADR in this study. Inbaraj SD, et al, has mentioned $1.7 \%$ cases of Steroid induced Striae; other researchers have-not found any case of steroid damaged face. $^{18-22}$

In this study acute urticaria $(8.65 \%)$ was the third most common form of ADR which is similar to that reported by Hiware S, et al, (14.56\%), as well as by Ghosh S, et al, $(9.43 \%)$ but differs from Abanti, et.al who has reported it as fifth common ADR (5.6\%). ${ }^{18,19,22}$

Fixed drug eruption (7.79\%) was fourth most common type of ADR in this study. Abanti, et al, (25.42\%), Inbaraj SD, et al (25.40\%), Ghosh S, et al, (10\%) and Chatterjee S et al, $(25.16 \%)$ reported it to be the second commonest type. ${ }^{19-22}$

Alopecia (4.76\%) was the fifth common type of reaction in this study. Whereas others have not found Alopecia as ADR. ${ }^{18-22}$ Since In this study Anticancer drugs were found to be fifth leading cause of ADR and all cases of Alopecia was caused by anticancer drugs. However, other drugs may also cause alopecia, which has not been detected by our and other studies.

In this study, 29.43\% cases of ADR were Probable/likely, $69.26 \%$ were Possible and $1.29 \%$ cases of ADR were in the category of certain (Re challenge was done by the patients) as per WHO-UMC causality categories.

On the other hand, Hiware S, et al, have found $66.51 \%$ cases of ADRs as certain and they have also mentioned that they have not done Rechallenge in any case. ${ }^{18}$ Since, as per WHO-UMC causality categories, cases need to be confirmed as Certain if rechallenge is satisfactory (if necessary).
Hiware S et al, also mentioned $29.81 \%$ cases of cADRs as Probable/likely which is similar finding to our study. ${ }^{18}$

Abanti S, et al, has mentioned $18.9 \%$ cases as certain, $41.5 \%$ cases as Probable/ likely and $39.6 \%$ of cADRs as Possible. ${ }^{19}$

Chatterjee S, et.al, has found $26.79 \%$ cases as certain and remaining $73.20 \%$ cases as Probable. They have not categorized any cases as Possible. ${ }^{21}$

In this study, authors found that serious dermatological ADRs were associated with the use of Levitracetam $\{1$ case of Toxic Epidermal Necrosis (TEN) \}; Clindamycin (1 case of TEN); Paracetamol (1 case each of Stevens Johnson Syndrome [SJS], TEN, Angioedema); Ibuprofen (1 case-SJS,2 case-TEN,1 case of Angioedema); Levofloxacin, Ceftriaxone+ sulbactam, Phenytoin (1 case each of SJS); Leflunomide caused 1 case of EFD.

Our study shows that commonly prescribed drugs like Paracetamol and Ibuprofen are liable to cause serious cADRs.

Study done by Inbaraj S, et al, has found no occurrence of any serious dermatological ADR on the other hand Abanti $\mathrm{S}$, et al, has mentioned $32.04 \%$ of serious life threatening cADRs in their study. ${ }^{19,20}$

Whereas, in a study done by Chatterjee S, et al, Allopurinol (2), carbamazepine (5), nimesulide (1) and Phenytoin (4) were responsible for SJS and TEN. ${ }^{21}$

Hiware S, et al, has implicated Cotrimoxazole ( 5 cases of SJS) and Ampicillin (5 cases of Anaphylaxis with Angioedema) as major cause of serious cADR apart from Paracetamol (1 case of SJS) and Ibuprofen (1 case of Anaphylaxis with Angioedema). ${ }^{18}$

In this study, dermatological ADRs of mild to moderate nature $(86 \%)$ were caused by the top ten offending drugs. Anticancer drugs and Topical clobetasole with gentamicin did not cause a single Severe reaction.

This differs from Abanti S, et al, who has reported $40.16 \%$ as mild to moderate and $50.94 \%$ as severe dermatological ADRs. ${ }^{19}$ It also differs from Inbaraj S, et al, who has not found single severe dermatological ADR. ${ }^{20}$

Further studies involving different centers (secondary /tertiary, rural/urban, OPD/ Hospitalized Patients) will be able to provide a wide variety of the sample and would be able to reflect on pattern, offending drugs, severity and causality assessment regarding Dermatological ADRs.

\section{ACKNOWLEDGEMENTS}

Authors would like to acknowledge support received from Department of Dermatology of SAIMS Medical Collegeand PGI, Indore, India. 
Funding: No funding sources

Conflict of interest: None declared

Ethical approval: The study was approved by the Institutional Ethics Committee

\section{REFERENCES}

1. Wu WK, Pantaleo N. Evaluation of outpatient adverse drug reactions leading to hospitalization. Ame J Health-System Pharm. 2003 Feb 1;60(3):253-9.

2. Gharaibeh MN, Greenberg H, Waldman SA. Adverse drug reactions: A review. Dru Inf J. 1998;32:323-38.

3. Protocol for National Pharmacovigilance programme version 1; Central Drug standard Control organization. Directorate General of Health services, Ministry of Health and family Welfare, Govt. of India: Nov 2004.

4. Chhabra SK. Adverse drug reactions and events. In: Ray A, Gulati K, editors. Pharmacovigilance: An update. New-Delhi; 2004:86-97.

5. Nebeker JR, Barach P, Samore MH. Clarifing adverse drug events: A clinician 's guide to terminology, documenteion and reporting Ann Intern Med. 2004;140:795-801.

6. Bhattacharya SK. Safety Profile of Drugs. In: Ray A. Gulati K. editors. Pharmacovigilance: An update. New Delhi; 2004:98-111.

7. Hartwig SC, Siegel J, Schnedider PJ. Preventability and severity assessment in reporting adverse drug reactions. Am J Hosp Pharm. 1992;49:2229-32.

8. Po ALW, Kendall MJ. Causality assessment of adverse effects: when is re-challenge ethically acceptable? Lancet. 1999;354(9179):683.

9. Parthsarathi G, Gogtay N. Causality assessment of adverse drug reactions. Proceedings of the national Training Course on Pharmacovigilance; Mumbai, India; 2005:17-21.

10. Naldi L, Conforti A, Venegoni M, Troncon MG, Caputi A, Ghiotto E, et al. Cutaneous reactions to drugs.An analysis of Spontaneous reports in four Italian regions. Br J Clin Pharmacol. 1999;48:839-46.

11. Stewart RB, May FE, Cullen SI. Dermatologic adverse drug reactions in Hospitalized Patients. Am J Hospitalized Patients. Am J Hosp Pharm. 1979;36:609-12.

12. Arndt KA, Jick H. Rates of Cutaneous reactions to drugs. A report from the Boston Collaborative Drug Survillance Program. JAMA. 1976;235:918-23.
13. Roujeau, JC, Stern, RS. Severe adverse cutaneous reactions to drugs. N Engl J Med. 1994;331:1272.

14. Levenson DE, Arndt KA, Stern RS. Cutaneous manifestations of adverse drug reactions. Immunol Allergy Clin N A Mer. 1991;11:493-507.

15. Patel BM. Skin rash with infectious mononucleosis and ampicillin. Pediatrics. 1967;40:910-1.

16. Bigby M, Jick S, Jick H, Arndt K. Drug induced cutaneous reaction. J Am Med Assoc. 1986;256:335863.

17. Fattinger K, Roos M, Vergeres P, Holenstein C, Kind $\mathrm{B}$, Masche U, et al. Epidemiology of drug exposure and adverse drug reactions in two swiss departments of internal medicine. $\mathrm{Br} \mathrm{J}$ Clin Pharmacol. 2000;49(2):158-67.

18. Hiware S, Shrivastava M, Mishra D, Mukhi J, Puppalwar G. Evaluation of cutaneous drug reactions in patients visiting out patient departments of Indira Gandhi Government Medical College and Hospital (IGGMC and H), Nagpur. Ind J Dermatol. 2013 Jan;58(1):18-21.

19. Saha A, Das NK, Hazra A, Gharami RC, Chowdhury SN, Datta PK. Cutaneous adverse drug reaction profile in a tertiary care out patient setting in eastern India. Ind J Pharmacol. 2012 Nov;44(6):792-7.

20. Inbaraj SD, Muniappan M, Muthiah NS, Arul Amutha GJ. Pharmacovigilance of the cutaneous drug reactions in outpatients of dermatology department at a tertiary care hospital. J Cli Diagno Resear: JCDR. 2012 Dec;6(10):1688-91.

21. Chatterjee S, Ghosh AP, Barbhuiya J, Dey SK. Adverse cutaneous drug reactions: A one year survey at a dermatology outpatient clinic of a tertiary care hospital. Ind J Pharmacol. 2006 Nov 1;38(6):429-31.

22. Ghosh S, Acharya LD, Rao PG. Study and evaluation of the various cutaneous adverse drug reactions in Kasturba hospital, Manipal. Ind J Pharmaceu Scienc. 2006;68(2):212-5.

Cite this article as: Bharani KR, Chandel NR, Goyal CA. Dermatological adverse drug reactions in tertiary care hospital: an analysis of causality and severity. Int J Basic Clin Pharmacol 2018;7:1620-5. 